\title{
DYNAMIC RHEOLOGICAL PROPERTIES OF SODIUM PYROPHOSPHATE- MODIFIED BENTONITE SUSPENSIONS FOR LIQUEFACTION MITIGATION
}

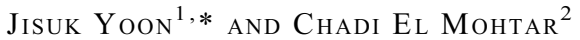 \\ ${ }^{1}$ Fugro Consultants, Inc., 6100 Hillcroft, Houston, TX 77081, USA \\ 2 Department of Civil, Architectural and Environmental Engineering, The University of Texas at Austin, \\ Austin, TX 78712-0280, USA
}

\begin{abstract}
The delivery of plastic fines such as bentonite into loose saturated granular soil deposits is an effective method for mitigating the liquefaction phenomenon. While the bentonite should be injected into the deposits in the form of a concentrated suspension, such application is limited in practice because of the low mobility of the suspension. The initial mobility of the bentonite suspension should be managed in order to increase the penetration depth. On the other hand, the suspension needs to maintain its thixotropic nature to improve the resistance of the treated soils under cyclic loading over time. The objective of the present study was to investigate the dynamic rheological properties of the bentonite suspensions modified with an ionic additive, sodium pyrophosphate (SPP), to evaluate a possible application of the modified suspensions in mitigation of liquefaction. In the present study, the storage and loss modulus of SPP-modified bentonite suspensions were measured using a strain-sweep (oscillatory shear) technique. Bentonite suspensions with clay contents of $5,7.5,10$, and 12 wt.\% (by total weight of suspension) were tested at various SPP concentrations ( 0 to $4 \mathrm{wt} . \%$ by weight of dry bentonite). The time-dependent behavior of the suspensions was evaluated with a critical storage modulus at various resting times ( 0 to $480 \mathrm{~h})$. The results showed that the initial critical storage modulus decreased significantly with increasing SPP concentrations, but the reduced critical storage modulus increased gradually with resting times. This initial reduction in critical storage modulus is attributed to a reduction of the inter-aggregated 3-D networks due to the presence of SPP; the amount of 3-D network formed in a suspension governs the critical storage modulus. With time, the networks are formed gradually, resulting in recovery of critical storage modulus. The normalized modulus was degraded more slowly in the modified suspensions than in the unmodified suspensions, which is a desirable property of the suspensions for mitigation of liquefaction.
\end{abstract}

Key Words-Bentonite Suspension, Liquefaction Mitigation, Permeation Grouting, Sodium Pyrophosphate, Thixotropy.

\section{INTRODUCTION}

Liquefaction occurs in loose saturated granular soil deposits due to the buildup of excess pore-water pressures during earthquakes. This phenomenon causes excessive horizontal and vertical ground deformations, resulting in the sinking and tilting of buildings, bridges, pipelines, and retaining structures (Kramer, 1996). The delivery of plastic fines into the deposits is one of the effective methods for mitigating this phenomenon. The plastic fines placed in the pore space reduces the generation of excess pore-water pressures, improving the cyclic resistance of the deposits (Polito, 2003; Haldavnekar et al., 2003; El Mohtar et al., 2008). El Mohtar et al. (2008) reported that the cyclic resistance of Ottawa sand specimens mixed with 3 to 5 wt. $\%$ dry bentonite (sand relative density of $30-35 \%$ ) increased significantly compared to that of clean sand. For such an application, the plastic fines such as bentonite are delivered into sand deposits in the forms of concentrated suspensions. However, the application of a concentrated

\footnotetext{
* E-mail address of corresponding author: jyoon@fugro.com
} DOI: $10.1346 / \mathrm{CCMN} .2013 .0610411$ suspension (exceeding $5 \mathrm{wt} . \%$ ) is limited due to its low penetrability through soils. Therefore, the initial rheological properties of the suspensions such as yield stress (or modulus) and viscosity should be reduced to increase the penetration depth of the suspensions. On the other hand, the reduced rheological properties need to be recovered over time to achieve resistance to groundwater flow and cyclic loading. Gallagher and Mitchell (2002) and El Mohtar et al. (2013) showed that the cyclic strength of clean sands increased significantly after permeation with colloidal silica and bentonite suspensions. Specifically, El Mohtar et al. (2013) reported that the cyclic strength of the bentonite-treated sands increased with increasing resting time, attributed to the fact that the gel-like pore fluids, which become stiffer with time, restrained the contractive motions of sand particles, reducing the buildup of the excess porewater pressures.

Previous research has reported the effect of the various ionic additives on bentonite suspensions (Tchillingarian, 1952; Gonzalez and Martin-Vivaldi, 1963; Abend and Lagaly, 2000; Penner and Lagaly, 2001). Although the ionic additives tend to improve the mobility of the bentonite suspensions, the time-dependent behavior of the treated suspensions varies with the 
type and concentration of the ionic additive. The untreated bentonite suspensions showed much lower mobility compared to the suspensions treated with sodium hydroxide after $24 \mathrm{~h}$ (Gonzalez and MartinVivaldi, 1963). Tchillingarian (1952) observed complete flocculation in clay suspensions treated with a polyphosphate (sodium hexametaphosphate) compared to the complete deflocculation with sodium hydroxide after 3 days.

The rheological properties of the bentonite suspensions are controlled by microstructures formed by bentonite particles in the suspensions. Under appropriate conditions $(\mathrm{pH}$, type and concentration of electrolyte, etc.), bentonite particles in suspensions form either a continuous and integrated house of cards-type structure (van Olphen, 1977) or a band-like structure (Norrish, 1954; Weiss and Frank, 1961). The network structures consist of aggregated individual particle platelets arranged in a combination of sandwiched edge-edge aggregates of the stacks (Morris and Żbik, 2009). The inter-aggregate bonds contribute to form the 3-D network in the suspension and control the strength of the suspensions (Goh et al., 2011). The inter-aggregate bonds are broken in a partially reversible manner when the applied stress is beyond an elastic limit, affecting the mobility of the suspensions. These types of bonds are gradually recovered with resting times (Nguyen and Boger, 1985). However, a complete description of the time-dependent rheological behavior of the bentonite suspension is still lacking in the literature.

The objective of this study was to investigate the dynamic rheological properties of the bentonite suspensions modified with an ionic additive, sodium pyrophosphate (SPP), for evaluating a possible application of the modified suspensions in liquefaction mitigation. The SPP was selected to control the rheological properties of the concentrated bentonite suspensions because the SPP displays pronounced dispersing capability compared to other ionic additives such as sodium hydroxide and sodium silicate and may allow gradual formation of a 3-D network with time (Tchillingarian, 1952; Penner and Lagaly, 2001). The critical storage modulus of the modified bentonite suspensions was investigated by using an oscillatory shear (strain-sweep) technique. This test applies oscillatory strains by increasing amplitudes at a constant level of frequency. The shear stress is shifted by a phase angle $\delta$ with respect to the applied strain so that the shear stress can be expressed as the sum of an elastic component (in-phase, $G^{\prime}$ ) and a viscous component (out-of-phase, $G^{\prime \prime}$ ) with the applied strain. The critical storage modulus (storage modulus at a small strain plateau where the storage modulus is constant in a modulus-strain curve) was used to evaluate the time-dependent behavior of the modified bentonite suspensions because the critical storage modulus provides information on the flocculated 3-D network structures (elastic behavior of the suspensions at small strains). The rate of time-dependent increase in the 3-D network of bentonite suspensions was investigated using a kinetic model.

\section{EXPERIMENTAL PROGRAM}

\section{Materials}

Wyoming Na-bentonite (CP-200, CETCO, Wyoming, USA) was used in this study. The particles have a platy shape with an average diameter of usually $<1-2 \mu \mathrm{m}$ (Mitchell, 1993; Luckham and Rossi, 1999). The raw bentonite initially included large impurities $(>75 \mu \mathrm{m})$ so the bentonite was screened through a No. 200 sieve to minimize the impurities and their effects on the results (Abend and Lagaly, 2000; Clarke, 2008). This process produced $\sim 95 \mathrm{wt} . \%$ of particles of $<25 \mu \mathrm{m}$ and $50 \mathrm{wt} . \%$ of particles $<1 \mu \mathrm{m}$ (ASTM D422). While the presence of some additional impurities such as sodium carbonate could interfere with the SPP, no further purification or gradation was applied to simulate mass production of material for field applications. The $\mathrm{pH}$ measurements of the unmodified suspensions immediately after mixing showed a consistent alkalinity of 9.3 on average, with a standard deviation and COV (coefficient of variation) of 0.3 and 0.03 , respectively. The physical properties of the sieved bentonite are summarized in Table 1.

Chemical analysis (Table 2) was performed using a Philips/FEI XL30 Environmental Scanning Electron Microscope (FEI Company, Hillsboro, Oregon, USA) equipped with energy dispersive X-ray (EDX) analysis capability to characterize the chemical composition of the sieved bentonite powder. A Gaseous Secondary Electron (GSE) detector was used with the frame and spot mode of the EDX. The $\mathrm{Na} / \mathrm{Ca}$ molar ratio was 1.9.

Commercially available sodium pyrophosphate decahydrate $\left(\mathrm{Na}_{4} \mathrm{P}_{2} \mathrm{O}_{7} \cdot 10 \mathrm{H}_{2} \mathrm{O}\right)$ was used in the present study. The specific gravity and molecular weight of SPP

Table 1. Physical properties of Wyoming bentonite (CP-200).

\begin{tabular}{llll}
\hline Plastic limit & $38 \%$ & Cation exchange capacity $^{*}$ & $82.2-86.5 \mathrm{meq} / 100 \mathrm{~g}$ \\
Liquid limit & $440 \%$ & Specific surface area & $715 \mathrm{~m}^{2} / \mathrm{g}$ \\
Specific gravity & 2.7 & $\mathrm{pH}$ & 9.3 \\
Initial water content & $8.3 \%$ & Swelling capacity & $8 \mathrm{~mL} / \mathrm{g}$ \\
\end{tabular}

* Dohrmann et al. (2012) and **Blum and Eberl (2004) 
Table 2. Chemical analysis (wt.\%) of Wyoming bentonite (CP-200).

\begin{tabular}{lc}
\hline $\mathrm{O}$ & 53.05 \\
$\mathrm{Na}$ & 2.27 \\
$\mathrm{Mg}$ & 1.52 \\
$\mathrm{Al}$ & 9.07 \\
$\mathrm{Si}$ & 28.77 \\
$\mathrm{P}$ & 0.46 \\
$\mathrm{~S}$ & 0.43 \\
$\mathrm{Cl}$ & 0.09 \\
$\mathrm{~K}$ & 0.52 \\
$\mathrm{Ca}$ & 1.2 \\
$\mathrm{Ti}$ & 0.15 \\
$\mathrm{Cr}$ & 0.11 \\
$\mathrm{Mn}$ & 0.2 \\
$\mathrm{Fe}$ & 2.31 \\
$\mathrm{Total}$ & 100 \\
$\mathrm{Na} / \mathrm{Ca}$ & 1.9 \\
& \\
\hline
\end{tabular}

are 1.8 and 446.06 , respectively. A 5 wt.\% SPP solution was prepared in advance and the appropriate amount of solution was added to the water and bentonite to increase the accuracy of the measurement. The average $\mathrm{pH}$ of 5 wt.\% solution measured using a JENCO $60 \mathrm{pH}$ meter was 9.5. Deionized water, with constant ionic concentration of $2 \times 10^{-5} \mathrm{mM}$, was used for preparing all the bentonite suspensions and SPP solution.

\section{Sample preparation}

The rheological properties of bentonite suspensions modified with SPP were measured at various bentonite (5, 7.5, 10, and 12 wt.\%) and SPP (0 to 4 wt.\%) concentrations, and resting times $(0-480 \mathrm{~h})$. The clay content of the bentonite suspension was calculated as the weight ratio of bentonite to the total weight of suspension, and the concentration of SPP was calculated as the weight ratio of SPP to the dry bentonite. In the calculation of the bentonite fraction, the initial water content of bentonite was taken into account. The screened bentonite powder was mixed with de-ionized water and SPP in three steps; each step consisted of 5 min of high shear mixing (Hamilton Beach 950 spindle mixer, Southern Pines, NC, USA) of the suspension followed by manual scraping of the sides and base of the mixing cup to remove bentonite flocs which had become attached. For samples rested for extended periods of time before testing, the suspensions were poured into cups manufactured specifically for this study. The cups were identical in size to the cup used for the vane tests in the rheometer (see the next section for dimensions and details). Mineral oil was added to the top of the bentonite suspensions to reduce any evaporation from the samples, and then the cups were sealed tightly and stored at room temperature in a dark cabinet which was free of vibration. All suspensions were rested for a given period of time without shearing.
Test equipment

A Physica MCR 301 rheometer (Anton Paar, Graz, Austria) was used in the present study. Vane geometry was used to measure the dynamic properties of the suspensions. The vane used had six blades, each $1 \mathrm{~mm}$ thick and $16 \mathrm{~mm}$ long. The vane radius was $11 \mathrm{~mm}$, resulting in a $3.46 \mathrm{~mm}$ gap between the cup and the vane. The cups manufactured for long-term resting of samples were $80 \mathrm{~mm}$ long and $29 \mathrm{~mm}$ in internal diameter. The sample volume was maintained at $37 \mathrm{~mL}$, which allowed the vane to penetrate approximately twice its length into the suspension. All tests were performed at $22^{\circ} \mathrm{C}\left( \pm 0.03^{\circ} \mathrm{C}\right)$.

\section{EXPERIMENTAL PROCEDURES}

A series of oscillatory shear tests was conducted at a constant oscillation rate of $1 \mathrm{~Hz}$ over the range of strains (strain-sweep). The critical storage modulus was determined from a small strain plateau where the storage modulus $\left(G^{\prime}\right)$ was constant (Figure 1). The oscillatory shear stress at the small strain amplitude of $0.01 \%$ was applied for $2 \mathrm{~min}$ before testing. The pre-shearing provided a consistent initial state in the sample prior to the measurement by allowing partial recovery of microstructures disturbed during insertion of the vane into the sample (Clarke, 2008; Yoon and El Mohtar, 2012). After the pre-shearing, the strain was increased stepwise, recording six points per log cycle. No variation in frequency was applied because Geier (2004) observed that the rheological behavior of bentonite suspensions is independent of frequency.

\section{MODELING OF MODULUS BUILD-UP}

The rate of structural build-up is another way to investigate the time-dependent response of the suspensions. In this study, the Leong (1988) model, which was originally developed to estimate the yield-stress recovery of brown coal suspensions, was modified to

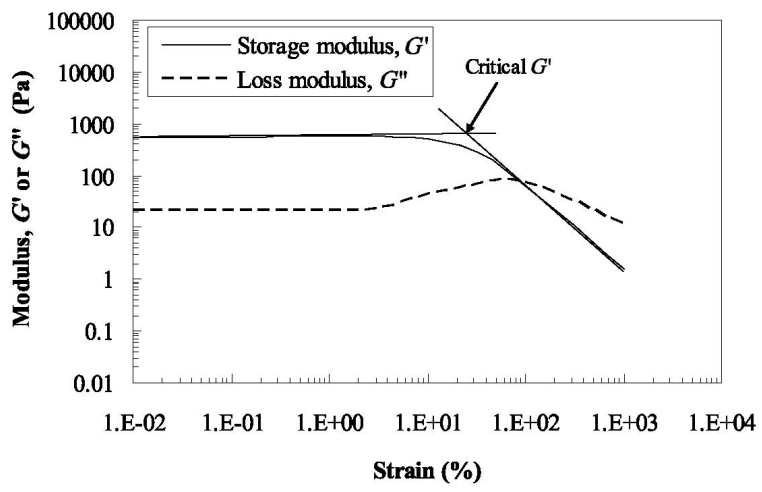

Figure 1. Example of how to determine the critical storage modulus in a strain-sweep test using vane geometry: $10 \mathrm{wt} \%$ bentonite suspension. 
characterize the effect of SPP on the rate of the structural build-up. The 3-D networks were assumed to govern the critical storage modulus of bentonite suspensions, similar to yield stress. This model was chosen because: (1) it is based on the network structure in suspensions (Smoluchowski coagulation theory); and (2) utilizes one simple parameter that can be useful to investigate the rate of the structural build-up. However, this model does not capture the increase of structure for a short resting time because it utilizes second-order kinetics, and the predicted values are less accurate for long resting times because $G_{\text {crit, } \infty}^{\prime}$ used in the model must be obtained for a finite time (de Kretser and Boger, 2001).

$$
G_{\text {crit }}^{\prime}(t)=G_{\text {crit }, \infty}^{\prime}\left(1-\frac{1-\left(\frac{G_{\text {crit }, \infty}^{\prime}}{G_{\text {crit }}^{\prime \prime}}\right)^{3 / 2}}{1+K_{\mathrm{r}} t}\right)^{2 / 3}
$$

where $G_{\text {crit }}^{\prime}(t)$ is the critical storage modulus at time $t$, $G^{\prime}{ }_{\text {crit, } \infty}$ is the critical storage modulus at infinite time $t$, $G^{\prime}{ }_{\text {crit }}$ is the critical storage modulus at time $t=0$, and $\mathrm{K}_{\mathrm{r}}$ is the recovery rate constant (1/time).

The critical storage modulus at long resting times could not be captured fully because the regression analyses used by de Kretser and Boger (2001) produced significant errors in evaluation of $G^{\prime}{ }_{\text {crit }, \infty}$ due to the very non-linear relationship between $1 / G^{\prime}$ crit and $1 / t$. To overcome this limitation, a root-mean-square error method was used to match the experimental data to the model in this study. $G_{\text {crit, } \infty}^{\prime}$ was considered as an unknown value (along with the recovery rate parameter, $\mathrm{K}_{\mathrm{r}}$ ) to investigate the discrepancy of $G^{\prime}{ }_{\text {crit, } \infty}$ and critical storage modulus at long resting times.

\section{RESULTS AND DISCUSSION}

\section{Effect of SPP on critical storage modulus}

The critical storage moduli decreased significantly from $73.9,571.5$, and $1915 \mathrm{~Pa}$ to $0.1,0.5$, and 2.4 with the addition of 1,3 , and 4 wt. $\%$ SPP, respectively (Figure 2a). The addition of 1 and 3\% SPP for 10 and 12 wt.\% suspensions produced a similar value to that of 5 wt. $\%$ suspension. The modulus $\left(G^{\prime}\right.$ or $\left.G^{\prime \prime}\right)$-strain $(\gamma)$ curves for the $10 \mathrm{wt} . \%$ suspension modified with $2 \mathrm{wt} . \%$ SPP (Figure 2b) showed that the loss modulus $\left(G^{\prime \prime}\right)$ became larger than the storage modulus $\left(G^{\prime}\right)$, implying that the suspensions behave like liquid. The results imply that the mobility of the suspensions could be significantly improved with a very small amount of SPP (0-4 wt.\%). However, the effect of SPP becomes small as the concentration of SPP increases. For instance, the 12 wt. $\%$ suspensions displayed $\sim 99.8 \%$ reduction in critical storage modulus with 3 wt. $\%$ SPP compared to $0.1 \%$ more reduction with $4 \mathrm{wt} . \% \mathrm{SPP}$, indicating that the effect of SPP is minimal beyond a threshold percentage of SPP. Yoon (2011) reported that the yield stress of the suspensions at 1,3 , and 4 wt.\% for $7.5,10$, and 12 wt.\% suspensions reached approximately zero and the yield stresses did not increase with the excessive addition of SPP (2, 5, and 7 wt.\% SPP for 7.5, 10, and 12 wt.\% bentonite suspensions). Based on this observation, the SPP concentrations of 1,3 , and 4 wt.\% for 7.5 , 10 , and 12 wt. $\%$ suspensions were mainly used through this study as an upper-limit dosage of SPP. The combination of SPP will produce the maximum permeation of the suspensions through sands because the maximum penetration distance of grouts (i.e. cementbased suspensions or chemical solutions) is inversely proportional to the yield stress of the grout (Axelsson and Gustafson, 2007).

\section{TIME-DEPENDENT BEHAVIOR}

The storage modulus $\left(G^{\prime}\right)$-strain $(\gamma)$ and phase angle $(\delta)$-strain $(\gamma)$ curves for the modified $12 \mathrm{wt} \%$ suspensions (4 wt.\% of SPP) at different resting times (Figure $3 \mathrm{a}, \mathrm{b}$ ) showed that the storage modulus of the modified suspensions increased even at the short resting times $(0.5$ and $1 \mathrm{~h})$ and the phase angles decreased
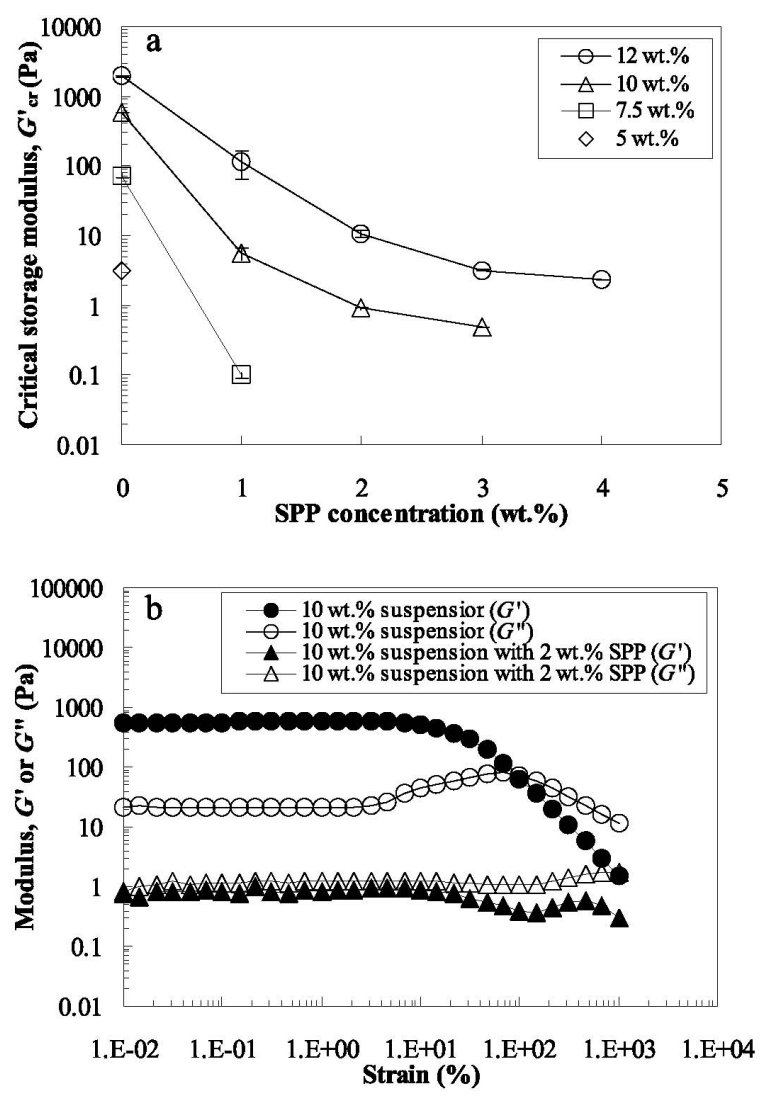

Figure 2. (a) Critical storage modulus of 5, 7.5, 10, and $12 \mathrm{wt} \%$ bentonite suspensions with various SPP concentrations ( $0-4$ wt.\%) measured immediately after mixing; and (b) modulus $\left(G^{\prime}\right.$ or $\left.G^{\prime \prime}\right)$-strain curves $(\gamma)$ for $10 \mathrm{wt} . \%$ bentonite suspensions with 0 and 2 wt. \% SPP. 

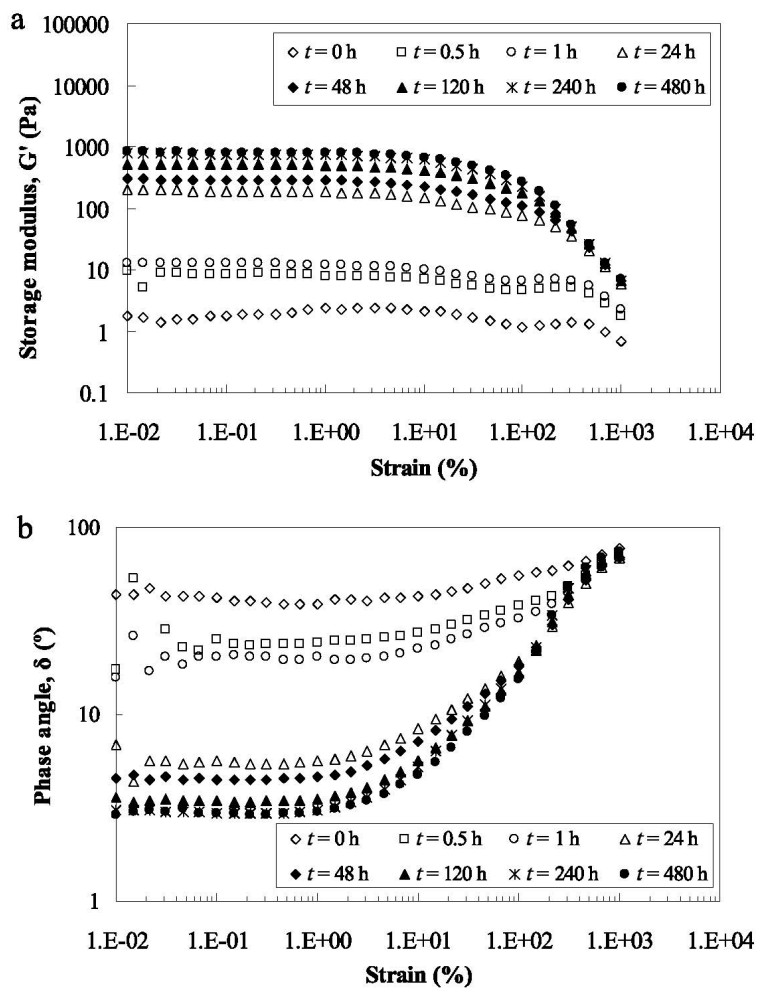

Figure 3. (a) Storage modulus $\left(G^{\prime}\right)$-strain $(\gamma)$ curves; and (b) phase angle $(\delta)$-strain $(\gamma)$ curves for 12 wt.\% bentonite suspensions with 4 wt.\% SPP with resting times.

rapidly $\left(<45^{\circ}\right)$. After $24 \mathrm{~h}$, the rate of increase in storage modulus and the rate of decrease in phase angle become small. From this time, the phase angle increased suddenly when the applied stress exceeded an elastic limit compared to the gradual increase in phase angle at short resting times $(0.5$ and $1 \mathrm{~h})$. After $24 \mathrm{~h}$, the storage moduli at larger strains (beyond 300\%) tended to be converged, but the moduli at the strain of $1000 \%$ were still greater than those of the initial state. The degradation of the normalized storage modulus (Figure 4) revealed that the normalized shear moduli in both the modified and unmodified suspensions were degraded as strain increased. While the unmodified $12 \mathrm{wt} . \%$ suspensions showed a narrow band with time, the modified suspensions showed large variations. The rate of modulus degradation in modified suspensions showed more gradual change than that in unmodified suspensions after $24 \mathrm{~h}$. The elastic range of both suspensions decreased with increased resting time, but the modified suspensions showed a wider range of elastic behavior $(2-1000 \%)$ than the unmodified suspensions $(1-2 \%)$, depending on the resting times. The smaller reduction in storage modulus of the modified suspensions indicates that the modified suspensions in pore space will lose less stiffness than the unmodified suspensions at the same cyclic strain.

This time-dependent behavior of bentonite suspensions is shown more clearly by investigating the evolution of critical storage modulus at different resting times (Figure 5a,b). While the rheological behavior of the bentonite suspensions can be affected by the $\mathrm{pH}$ of the suspensions, Kelessidis et al. (2007) reported that for concentrated bentonite suspensions (6.42 wt.\%), with $\mathrm{pH}$ values beyond 'natural' $\mathrm{pH}(\sim 9.0)$, little difference was observed in $\mathrm{pH}$ values between the moment of mixing and full hydration (16 h). In addition, Clarke (2008) reported that the $\mathrm{pH}$ of the SPP-modified suspensions did not vary significantly with the resting time and SPP concentrations. Therefore, the effect of $\mathrm{pH}$ was not examined in the present study.

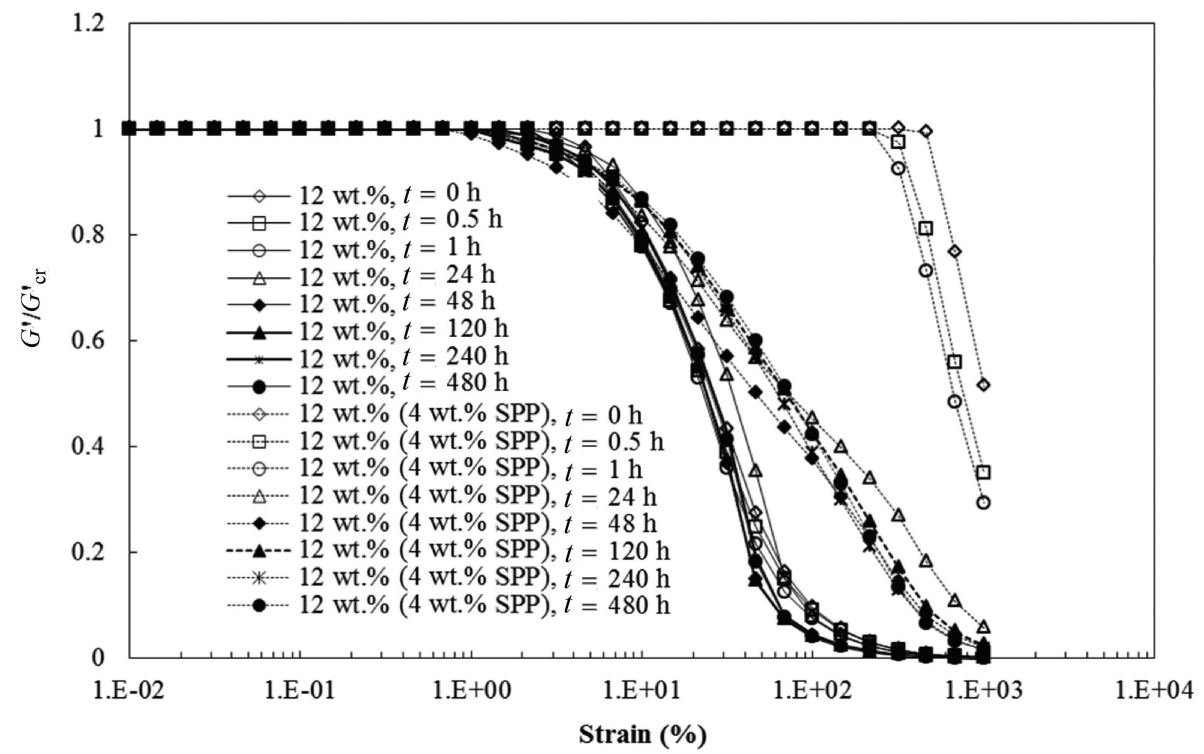

Figure 4. Normalized modulus degradation curves for $12 \mathrm{wt} . \%$ bentonite suspensions with 0 and 4 wt.\% SPP with resting times. 

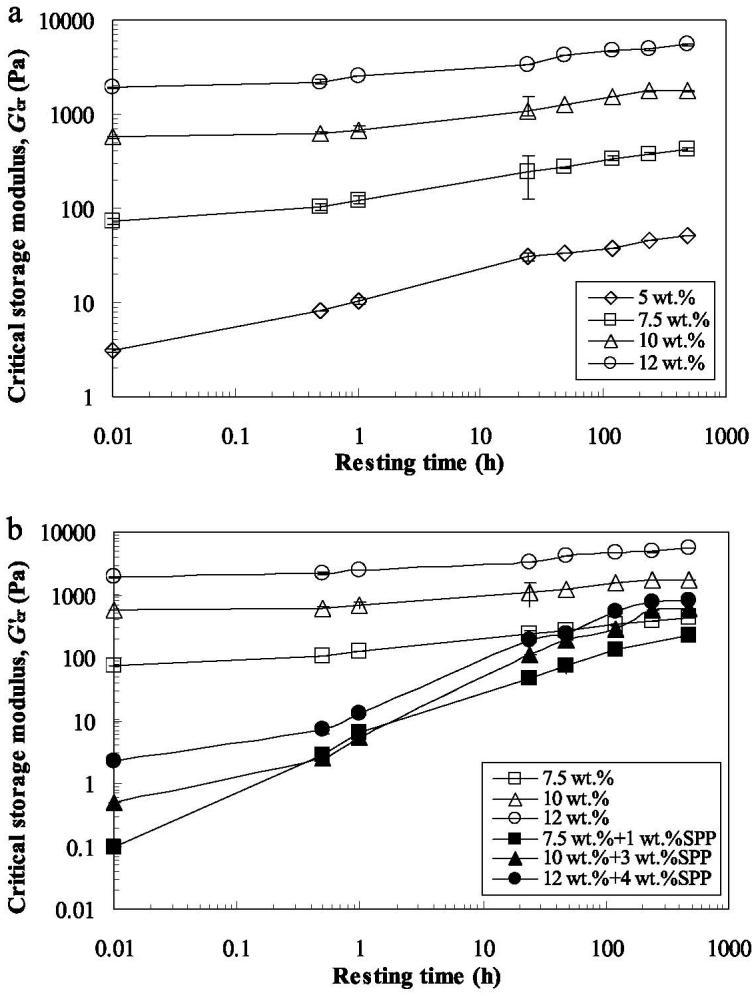

Figure 5. Evolution of critical storage modulus for (a) 5, 7.5, 10, and $12 \mathrm{wt} \%$; and (b) comparison of the modified and unmodified bentonite suspensions.

Each of the data points shown on the plot is an average of at least three independent measurements on three different samples. On average, the COV was $0.01-0.48$, showing greater $\mathrm{COV}$ for short resting times. The critical storage moduli of the unmodified 5, 7.5, 10, and $12 \mathrm{wt. \%}$ bentonite suspensions increased gradually from 3.1, 73.9, 571.5, and $1915 \mathrm{~Pa}$ to 52.3, 423.5, 1770, and $5510 \mathrm{~Pa}$, respectively, after $480 \mathrm{~h}$ (Figure 5a). All suspensions showed a large increase in the critical storage modulus at short resting times, and then the rate of increase in critical storage modulus was reduced as time elapsed. The critical storage moduli of the unmodified and modified 7.5, 10, and 12 wt.\% suspensions with 1,3 , and 4 wt. $\%$ SPP, respectively, increased with time, approaching those of the unmodified bentonite suspension (Figure 5b). After $480 \mathrm{~h}$, the critical storage modulus of the modified suspensions reached $40-300 \%$ of the initial critical storage modulus in the unmodified suspensions; the critical storage modulus of 7.5 wt. $\%$ suspension with $1 \mathrm{wt} . \%$ SPP reached the initial critical storage modulus after $48 \mathrm{~h}$. Because all the measurements were performed over such a long time scale, sedimentation of bentonite particles was a concern; the bentonite fraction at the bottom of the storage cups was measured by taking a portion of suspensions at the bottom of the storage cup and drying it out. The average ratio of initial bentonite fraction and bentonite fraction at the bottom of cup after resting was 1.05 with standard deviation and COV of 0.019 and 0.018 , respectively. Before that, a visual inspection was conducted, resulting in no distinct sedimentation in any suspensions, implying that sedimentation of bentonite particles up to $480 \mathrm{~h}$ is negligible.

At short resting times, all suspensions showed a large increase in critical storage modulus, and then the rate of increase in critical storage modulus was reduced as time elapsed. This phenomenon is mainly due to the hydration of bentonite particles that takes place within 16 to $24 \mathrm{~h}$. The bentonite suspensions used in this study were not hydrated to simulate the immediate use of bentonite in the field application (Kelessidis et al., 2007). Moreover, this study tried to capture the change of microstructures starting from the mixing time, which represent the suspension properties from the permeation stage to a certain resting stage beyond permeation in field applications. A more dispersed suspension is formed during hydration because the attractive forces between the separate platelets are weakened due to the adsorption of water molecules between the inter-layers of the clay platelets, leading to swelling (Madsen and MüllerVonmoos, 1989; Luckham and Rossi, 1999). The amount of cations in bentonite such as those of calcium and iron controls the degree of separation in bentonite particles; bentonite with more ions experiences less separation (Lutz, 1939; Madsen and Müller-Vonmoos, 1989). With SPP, after hydration, repulsive forces between the separate platelets increased, retarding the buildup in critical storage modulus.

The thixotropy ratios (the ratio of the critical storage modulus at a given resting time to that at a zero resting time) for the different bentonite fractions (Figure 6) indicate that the amount of structural buildup varies with bentonite fractions and SPP concentrations. While the critical storage moduli of the diluted suspensions were small, the thixotropy ratios were larger than those for the concentrated suspensions. While the absolute critical moduli were small in the modified suspensions, the

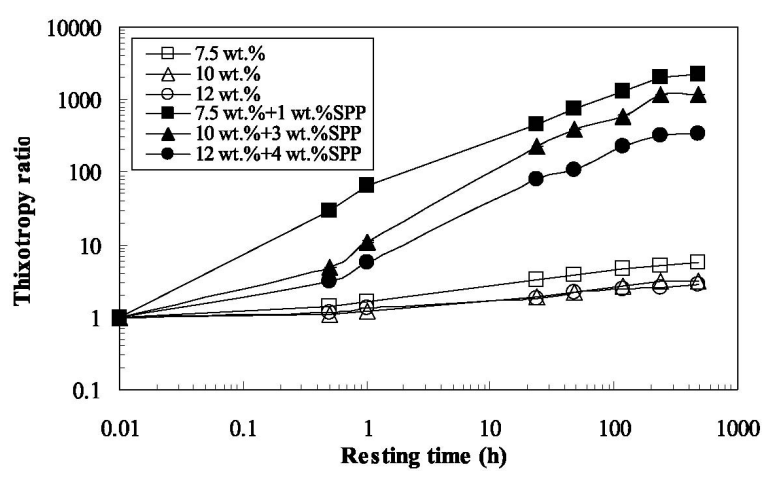

Figure 6. Thixotropy ratio for unmodified $(7.5,10$, and 12 wt.\%) and modified $(7.5,10$, and 12 wt. $\%$ with 1,3 , and 4 wt.\% SPP) suspensions. 
thixotropy ratio became much larger with the addition of SPP. This behavior was similar to what was observed in the suspensions with small bentonite fractions. This observation implies that the initial rapid increase in critical storage modulus was affected, not only by the hydration of bentonite particles, but also by the Brownian motion. As time elapsed, the Brownian motion of particles became constrained due to developed network structures; the measured thixotropy ratio in concentrated suspensions was lower than that of the diluted suspensions. In addition, the greater thixotropy ratios indicate the increased Brownian motion in the modified suspensions due to reduction in network structures.

\section{MODELING RESULT}

The comparison of the model with experimental data for $7.5,10$, and 12 wt. $\%$ suspensions with 1, 3, and 4 wt.\% of SPP (Figure 7) showed that the model could capture the overall behavior well. However, discrepancies still exist for short resting times due to the limitation of the Leong (1988) model mentioned in the section on modeling of modulus build-up. The recoveryrate parameter $\left(\mathrm{K}_{\mathrm{r}}\right)$, the predicted critical storage modulus at infinite time $\left(G_{\text {crit }, \infty}^{\prime}\right)$, and the ratio between the predicted critical storage modulus at infinite time and the measured critical storage modulus at $480 \mathrm{~h}$ obtained from the present study (Table 3 ) showed that $480 \mathrm{~h}$ could be considered as an infinite time because it produced a sufficiently small value for $1 / t(\sim 3.5 \times$ $\left.10^{-5} / \mathrm{min}\right)$. While the recovery rate decreased as bentonite fractions increased, the greater particle motion produced greater thixotropy ratios; de Kretser and Boger (2001) observed similar results in Na-montmorillonitebased suspensions. Increasing the SPP content for a given suspension resulted in an increase of the characteristic recovery time $\left(1 / \mathrm{K}_{\mathrm{r}}\right)$. The measured critical storage moduli at $480 \mathrm{~h}$ were also close enough (standard deviations of 0.1 ) to the predicted values at the time (considered as critical storage modulus at infinite time).

Overall, the rheological behavior of the SPP-modified bentonite suspensions implied that the modified suspensions would be appropriate for the proposed

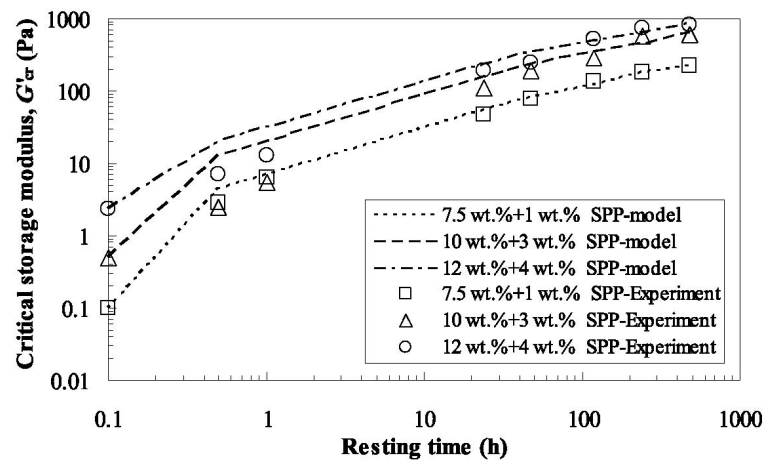

Figure 7. Modified Leong model fitted with experimental data.

application due to the large initial mobility and the recovery of stiffness over time.

\section{SUMMARY AND CONCLUSIONS}

The dynamic rheological properties of the modified bentonite suspensions were investigated using vane geometry. The addition of a small amount of SPP reduced significantly the critical storage modulus and increased the phase angle in bentonite suspensions. The reduction in critical storage modulus tended to converge after a threshold percentage of SPP (1, 3, and 4 wt. $\%$ for $7.5,10$, and 12 wt. $\%$ bentonite suspensions).

The reduced critical storage modulus was recovered gradually with time. The concentrated suspensions produced a lower rate of increase in the critical storage modulus (smaller thixotropy ratio) than the diluted suspensions with time; similarly, larger percentages of SPP induced greater degrees of build-up at a given resting time (higher thixotropy ratio). This observation can be explained through looking into the structural kinetics of the different suspensions. The constrained Brownian motions in the concentrated suspensions produced low thixotropy ratios. On the other hand, the SPP-modified suspensions, which showed a high degree of Brownian motion due to the reduction of interaggregate bonds (3-D network), produced greater thixotropy ratios than those in the unmodified suspensions.

The recovery rate of bentonite suspensions was determined based on the modified Leong model

Table 3. Recovery rate constant $\left(\mathrm{K}_{\mathrm{r}}\right)$, predicted critical storage modulus at infinite time, and ratios between measured (480 h) and predicted critical storage modulus.

\begin{tabular}{|c|c|c|c|c|c|c|c|c|c|c|c|c|c|}
\hline \multirow{2}{*}{\multicolumn{2}{|c|}{$\begin{array}{l}\text { Parameters } \\
\text { Suspension concentration (wt.\%) }\end{array}$}} & \multirow[b]{2}{*}{5} & \multicolumn{3}{|c|}{$-K_{\mathrm{r}}(1 / \mathrm{h})-$} & \multicolumn{4}{|c|}{ Predicted $G^{\prime}$} & \multicolumn{4}{|c|}{$\mathrm{P}\left(G_{\text {crit, } \infty}^{\prime}\right) / \mathrm{M}\left(G_{\text {crit, } \infty}^{\prime}\right.$ at $\left.480 \mathrm{~h}\right)$} \\
\hline & & & 7.5 & 10 & 12 & 5 & 7.5 & 10 & 12 & 5 & 7.5 & 10 & 12 \\
\hline \multirow[t]{4}{*}{ SPP (wt.\%) } & 0 & 0.031 & 0.024 & 0.023 & 0.027 & 49 & 418 & 1824 & 5400 & 0.94 & 0.99 & 1.03 & 0.98 \\
\hline & 1 & N.A. & 0.006 & N.A. & N.A. & N.A. & 236 & N.A. & N.A. & N.A. & 1.02 & N.A. & N.A. \\
\hline & 3 & N.A. & N.A. & 0.006 & N.A. & N.A. & N.A. & 639 & N.A. & N.A. & N.A. & 1.07 & N.A. \\
\hline & 4 & N.A. & N.A. & N.A. & 0.007 & N.A. & N.A. & N.A. & 853 & N.A. & N.A. & N.A. & 1.06 \\
\hline
\end{tabular}


(1988). The results showed that the recovery rate increased with bentonite concentrations and decreased with SPP concentrations, indicating that the suspensions having significant Brownian motion (high-percentageof-SPP) have slower build up in critical storage modulus than the suspensions having little Brownian motion (low-percentage-of-SPP). In addition, the model could capture the overall time-dependent build-up of critical storage modulus in the bentonite suspensions by estimating critical storage modulus at infinite time from measured data. This may be useful to estimate long-term performance of grouts after injection into the soil pores.

In practice, the modified suspensions are injected into loose saturated soils at low pressures so that the reduction in the 3-D network helps to increase the penetration depth of grouts because yield stress, which is also a function of the 3-D network, is reduced with the SPP modification. The maximum penetration distance of grouts is inversely proportional to the yield stress of the grout. This indicates that the modified suspensions with 1, 3, and 4 wt.\% SPP concentrations have maximized propagation distance through soils due to the low yield stress, which controls the stoppage of grout flow. The reduced 3-D network increases with time, suppressing generation of excess pore-water pressures in sand pores during cyclic loading. However, the design of bentonite grouting should consider both the cyclic stress generated during a design earthquake event and the cyclic resistance of the treated soil at the cyclic stress due to the thixotropic nature of the bentonite grout. These observations support a possible application of the modified bentonite suspensions for liquefaction mitigation by (1) increasing penetration depth, and (2) reducing the possibility of liquefaction of the treated sands due to the time-dependent increase in stiffness of grouts in pore spaces.

\section{ACKNOWLEDGMENTS}

This work was partially supported by the National Science Foundation, Geomechanics and Geomaterials program, and Geothechnical Engineering program, under Grant No. 1254763. This support is gratefully acknowledged.

\section{REFERENCES}

Abend, S. and Lagaly, G. (2000) Sol-gel transitions of sodium montmorillonite dispersions. Applied Clay Science, 16, $201-227$

Axelsson, M. and Gustafson, G. (2007) Grouting with high water-cement ratios - literature and laboratory study. Report no. 2007:5, Chalmers University of Technology, Sweden.

Clarke, J.P. (2008) Investigation of time-dependent rheological behavior of sodium pyrophosphate-bentonite suspensions. M.S. thesis, Purdue University, West Lafayette, Indiana, USA.

de Kretser, R.G. and Boger, D.V. (2001) A structural model for the time-dependent mineral suspensions. Rheologica Acta,
40, $582-590$.

E1 Mohtar, C.S., Clarke, J.P., Bobet, A., Santagata, M., Drnevich, V., and Johnston, C. (2008) Cyclic response of a sand with thixotropic pore fluid. Geotechnical Earthquake Engineering and Soil Dynamics IV (GSP 181), May 18-22, Sacramento, California, USA, pp. 1-10.

El Mohtar, C., Bobet, A., Santagata, M., Drnevich, V., and Johnston, C. (2013) Liquefaction mitigation using bentonite suspensions. Journal of Geotechnical and Geoenvironmental. Engineering, 139, 1369-1380.

Gallagher, P.M. and Mitchell, J.L. (2002) Influence of colloidal silica grout on liquefaction potential and cyclic undrained behavior of loose sand. Soil Dynamics and Earthquake Engineering, 22, 1017-1026.

Geier, D.L. (2004) Rheological investigation of bentonite based suspensions for geotechnical applications. M.S. Thesis, Purdue University, West Lafayette, Indiana, USA.

Goh, R., Leong, Y.K., and Lehane, B. (2011) Bentonite slurries-zeta potential, yield stress, adsorbed additive and time-dependent behaviour. Rheologica Acta, 1, 1-10.

Gonzalez, J.L. and Martin-Vivaldi, J.L. (1963) Rheology of bentonite suspensions as drilling muds. Proceedings of a Conference held at Stockholm, Sweden, August 12-16, 1963, 2, p. 277, Macmillan, New York.

Haldavnekar, V., Bobet, A., Santagata, M., and Drnevich, V. (2003) Soil treatment with a thixotropic fluid: an autoadaptive design for liquefaction prevention. Proceedings of 11th International Conference on Soil Dynamics and Earthquake Engineering and $3 \mathrm{rd}$ Conference on Earthquake Geotechnical Engineering, Vol. II, pp. 553-560.

Kelessidis, V. C., Tsamantaki, C., and Dalamarinis, P. (2007) Effect of $\mathrm{pH}$ and electrolyte on the rheology of aqueous Wyoming bentonite dispersions. Applied Clay Science, 38, 86-96.

Kramer, S.L. (1996) Geotechnical Earthquake Engineering. Prentice-Hall, Inc., New Jersey, USA.

Leong, Y.K. (1988) Rheology of modified and unmodified Victorian brown coal suspensions. PhD thesis, Melbourne University, Melbourne, Australia.

Luckham, P.F. and Rossi, S. (1999) The colloidal and rheological properties of bentonite suspensions. Advances in Colloid and Interface Science, 82, 43-92.

Lutz, J.F. (1939) The effect of iron on some physico-chemical properties of bentonite suspensions. Soil Science Society of America Journal, 3, 7-12.

Madsen, F.T. and Müller-Vonmoos, M. (1989) The swelling behavior of clays. Applied Clay Science, 4, 143-156.

Mitchell, J.K. (1993) Fundamentals of Soil Behavior. $2^{\text {nd }}$ edition, John Wiley \& Sons Inc., New York.

Morris, G.E. and Żbik, M.S. (2009) Smectite suspension structural behavior. International Journal of Mineral Processing, 93, 20-25.

Nguyen, Q.D. and Boger, D.V. (1985) Thixotropic behaviour of concentrated bauxite residue suspensions. Rheologica Acta, 24, 427-437.

Norrish, K. (1954) The swelling of montmorillonite. Discussions of the Faraday Society, 18, 120-134.

Penner, D. and Lagaly, G. (2001) Influence of anions on the rheological properties of clay mineral dispersions. Applied Clay Science, 19, 131-142.

Polito, C.P. and Martin II, J.R. (2003) A reconciliation of the effects of non-plastic fines on the liquefaction resistance of sands reported in the literature. Earthquake Spectra. 19, $635-651$.

Tchillingarian, G. (1952) Study of the dispersing agents. Journal of Sedimentary Petrology, 22, 229-233.

van Olphen, H. (1977) An Introduction to Clay Colloid Chemistry. Wiley, New York. 
Weiss, A. and Frank, R. (1961) Uber den Bau der Gerüste in thixotropen Gelen. Zeitschrift für Naturforschung, 16, $141-142$

Yoon, J. (2011) Application of pore fluid engineering for improving the hydraulic performance of granular soils. Ph.D. dissertation, the University of Texas at Austin, USA.
Yoon, J.S. and El Mohtar, C. S. (2012) Time-dependent rheological behavior of modified bentonite suspensions. Proceedings of GeoCongress 2012, 1195-1204.

(Received 23 April 2013; revised 23 July 2013; Ms. 764; AE: M. Plötze) 